\title{
Avaliação de pastas de cimento Portland contendo cinza pesada moída
}

\author{
Portland cement pastes evaluation \\ containing ground bottom ash
}

\author{
Ronaldo Pilar ${ }^{1}$, Rudiele Aparecida Schankoski ${ }^{1}$, \\ Agostinho João Dal Moro ${ }^{2}$, Wellington Longuini Repette ${ }^{1}$
}

\author{
${ }^{1}$ Departamento de Engenharia Civil, Universidade Federal de Santa Catarina - UFSC, Rua João Pio Duarte Silva 250, \\ Córrego Grande, CEP 88040-900 Florianópolis, SC. \\ ${ }^{2}$ U. O. Engenharia de Manutenção - ENG \\ e-mail: ronaldo_pilar@hotmail.com,rudiele_as@yahoo.com.br, dalmoro@tractebelenergia.com.br,welling- \\ ton.repette.@gmail.com
}

\begin{abstract}
RESUMO
Neste trabalho avalia-se a influência da incorporação de cinza pesada moída, obtida da combustão de carvão mineral, em pastas de cimento Portland. A cinza pesada foi incorporada as pastas de cimento em três distribuições granulométricas distintas e dosadas para teores de substituição ao cimento, em volume, de 10\%, 30\% e 50\%. As pastas foram dosadas com duas relações água/aglomerante, em massa, de 0,35 e 0,40. As primeiras idades foram investigadas por calorimetria isotérmica. Após passarem por cura úmida, as pastas foram testadas por termogravimetria, resíduo insolúvel e resistência mecânica à compressão para as idades de 7, 28 e 91 dias de hidratação. Foi observado um aumento do grau de hidratação para as pastas produzidas com cinza pesada moída, independentemente da finura e do teor incorporado. O aumento de calor liberado e resistência à compressão, juntos com a redução do percentual de resíduo insolúvel, levaram a conclusão que cinza pesada moída apresentou, simultaneamente, atividade química e física junto a hidratação do cimento. Os resultados sugerem que a cinza pesada moída pode substituir em até 50\% o volume do cimento Portland sem redução da resistência mecânica aos 91 dias de hidratação.
\end{abstract}

Palavras-chave: Cimento Portland. Cinza pesada moída. Pozolanicidade.

\begin{abstract}
In this study, the influence of adding ground coal bottom ash in Portland cement pastes was evaluated. Blended cements were prepared with ground bottom ash of three distinct particle size distributions and substitutions, by volume, of $10 \%, 30 \%$, and $50 \%$. For each blended cements, pastes were prepared with water to binder ratios of 0.35 and 0.40 , by mass. Early age hydration was investigated by isothermal calorimetry. After being subject to wet curing, the pastes were tested for thermogravimetric analysis, insoluble residue content and compressive strength tests at 7, 28, and 91 days. Degree of hydration increased with the addition of ground bottom ash for all fineness and replacement contents. Increase in heat evolution and compressive strength, along with the decrease in the insoluble residue content, lead to the conclusion that the added ground bottom ash acted both chemically and physically in the hydration of the blended cements. The findings suggest that the ground bottom ash could replace up to $50 \%$ of the ordinary Portland cement without compromising compressive strength at 91 days of hydration
\end{abstract}

Keywords: Portland cement. Ground bottom ash. Pozzolanicity.

\section{INTRODUÇÃO}

O aumento populacional e o crescimento econômico dos países em desenvolvimento são os principais fatores que contribuem para o aumentando da demanda por recursos naturais. Segundo o IEO [1], o consumo mundial de energia sofrerá um acréscimo aproximado de 50\% entre os anos de 2012 e 2040. Dessa forma, torna-se essencial a busca por novos insumos e, principalmente, o desenvolvimento de tecnologias que possibilitam o reaproveitamento de rejeitos que demandam baixo consumo de energia para o seu beneficiamento. Nesse contexto enquadra-se a cadeia produtiva do cimento Portland, sendo um dos setores que mais emprega o uso 
de resíduos ou subprodutos de outros processos industriais.

Dentre a adições minerais destacam-se as pozolanas, que são materiais silicosos ou sílicoaluminosos que, se finamente moída e na presença de umidade, reagem quimicamente com o hidróxido de cálcio para formar compostos com propriedades ligantes [2]. A cinza volante, proveniente da queima de carvão pulverizado em usinas termoelétricas, é a adição pozolânica tradicionalmente adicionada na fabricação de cimentos compostos. Contudo, os rejeitos do processo de combustão do carvão não se resumem à cinza volante. Parte considerável de material precipita no fundo dos fornos de queima e é chamada cinza pesada.

Apesar da cinza pesada de carvão mineral apresentar composição semelhante à das pozolanas tradicionalmente empregadas na produção dos cimentos Portland compostos $[3,4,5,6]$, pouco se conhece sobre sua interação junto a hidratação do cimento. Os trabalhos a respeito da cinza pesada concentram-se em argamassas e concretos, o que dificulta determinar com precisão as ações químicas e físicas da cinza incorporada, uma vez que outros finos das misturas podem competir com a cinza e dificultar essa análise. KULA et al. [3] estudaram argamassas com incorporação de cinza volante e cinza pesada e observaram que as misturas apresentaram resistência mecânica à compressão semelhantes para todas as idades analisadas (1,3,7, 28 e 91 dias).

Os autores também observaram que o tempo de início e fim de pega das misturas não foram alterados pela incorporação de cinza pesada, quando comparados com misturas produzidas sem pozolanas, ao contrário do que ocorreu com a cinza volante. CHERIAF et al. [7] afirmaram que a cinza pesada possui atividade pozolânica significativa após os 28 dias de hidratação, sendo que aos 91 dias de hidratação foi observado um grande consumo de hidróxido de cálcio, em pastas de cinza pesada moída e hidróxido de cálcio. Também segundo os mesmos autores, o tratamento mecânico de trituração da cinza pesada promoveu ganhos substanciais na sua atividade pozolânica.

No que tange as reações químicas envolvendo materiais pozolânicas, pode-se dizer que são desencadeadas pelo ataque das hidroxilas à fração vítrea do material, composta principalmente por $\mathrm{Al}_{2} \mathrm{O}_{2}$ e $\mathrm{SiO}_{2}$, quebrando as ligações com os átomos de oxigênio, para formar íons, os quais reagirão com os íons $\mathrm{Ca}^{+2}[8,9$, 10]. Contudo, a interação das partículas pozolânicas dispersas na pasta de cimento não se resume apenas ao consumo de hidróxido de cálcio para produção de hidratos. As adições minerais podem atuar como pontos de nucleação para a precipitação dos produtos de hidratação do cimento Portland, pois suas partículas são menos reativas que as do cimento [11, 12]. Portanto, esse mecanismo tornaria a pasta mais homogênea e densa para uma dada distribuição de pequenos poros, facilitando o desenvolvimento das propriedades mecânicas, sem necessariamente estar atuando como uma pozolana.

GOLDMAN e BENTUR [13] estudaram a influência da incorporação de microfinos inertes e microssílica no incremento da resistência mecânica de pastas e concretos, e indicaram que parte da influência da microssílica deve-se ao seu efeito físico. Os autores também sugeriram que a incorporação de microfíler inerte ao concreto apresenta ação similar à incorporação de microssílica. Da mesma forma, ISAIA et al. [14] afirmaram que em concretos com $50 \%$ de incorporação de material pozolânico e resistência de 65 MPa, o valor obtido para o efeito físico supera o efeito pozolânico para as idades de 28 e 91 dias. Uma hipótese que explicaria os resultados citados anteriormente, segundo LAWRENCE et al. [12], é que a espessura da camada hidratada formada em torno do grão de cimento é reduzida quando estão presentes partículas finas de adição mineral. A hipótese sugere que a hidratação da fração anidra do cimento torna-se rapidamente dependente dos fenômenos de difusão, a qual é facilitada pela redução da espessura do envelope de hidratos, facilitando a hidratação do cimento.

Assim, o presente estudo buscou avaliar o potencial de incorporação da cinza pesada moída, em pastas de cimento Portland, por meio de análises que consigam identificar suas ações química e física.

\section{MATERIAIS E MÉTODOS}

Para o presente trabalho foi utilizado cimento Portland CP V (ABNT NBR 5733) [16] pelo fato de ser o cimento com a menor quantidades de adição mineral e não possuir cinza volante na sua composição, o qual é fabricado com clínquer, gesso e material carbonático. A cinza pesada foi proveniente do Complexo Termelétrico Jorge Lacerda (Tractebel Energia), localizado na cidade de Capivari de Baixo, Santa Catarina, Brasil.

Objetivando diminuir as variáveis deste estudo, toda a cinza, in natura, foi seca em estufa e, em seguida, homogeneizada. A cinza pesada passou pelo processo de moagem em um moinho de bolas, modelo AMBI 480 X 400, obtendo-se três lotes distintos de cinza pesada moída: cinza grossa (CG), cinza média (CM), cinza fina (CF). O lote de cinza fina possuía distribuição granulométrica similar à do cimento Portland utilizado. No item 3 são apresentados os valores percentuais da distribuição granulometria dos três lotes de cinza e do cimento CP V, junto com a densidade de cada material.

Foram produzidas pastas com relações água/aglomerante (a/ag) de 0,35 e 0,40. Para a relação a/ag de 0,35 foram dosadas pastas com três teores de substituição ao cimento: $10 \%, 30 \%$ e $50 \%$, para cada um dos três lotes de cinza e uma pasta de referência, contendo apenas cimento Portland. Para a relação a/ag igual a 
0,40 foi adotado somente o teor de $10 \%$ de substituição, para cada lote cinza, mais a pasta referência. Na Tabela 1 é apresentado as composições das catorze pastas do programa experimental. Nota-se que para o mesmo percentual de incorporação de cinza houve variação de massa entre os três lotes de cinza. Isso se deve pelo fato que a substituição do cimento por cinza ocorreu em volume e a massa específica de cada cinza pesada moída variou. Destaca-se que a relação a/ag de 0,40 foi a máxima suportada pelas misturas sem que ocorressem exsudação e segregação.

As misturas foram realizadas em misturador de eixo planetário. Os primeiros $30 \mathrm{~s}$ de mistura, em velocidade baixa, foram utilizados para homogeneizar o cimento e a cinza. Em seguida adicionava-se água e prosseguia-se com o processo de mistura por mais $30 \mathrm{~s}$, em velocidade baixa. Os próximos $30 \mathrm{~s}$ foram usados para raspar a cuba do misturador. Por fim, mais 45s de mistura em velocidade alta. Foram moldados para cada idade de ensaio três corpos de prova cilíndricos com diâmetro de $5 \mathrm{~cm}$ e altura de $10 \mathrm{~cm}$, e ensaiados à compressão aos 7, 28 e 91 dias. Também foram moldados corpos de prova prismáticos de $2 \mathrm{~cm}$ por 4,0 cm de base e $5 \mathrm{~mm}$ de altura, destinados às análises termogravimétricas e de resíduo insolúvel (RI), nas mesmas idades citadas anteriormente. Todos os corpos de prova foram adensados em mesa vibratória por 10 segundos.

As amostras foram desmoldadas após 24 horas da moldagem e mantidas em câmara úmida até as idades de 7, 28 e 91 dias. A hidratação foi interrompida empregando-se o processo freeze-drying [17, 18] para os testes de termogravimetria e resíduo insolúvel. As amostras de pasta congeladas foram liofilizadas e moídas em moinho vibratório de bolas e cuba de ágata de marca FRITSCH, modelo micro Pulverisette 0. As amostras foram armazenadas em dessecadores com sílica gel até as datas de ensaio.

Tabela 1: Proporção dos materiais para produção de 1 litro de pasta.

\begin{tabular}{l|c|c|c|c|c|c}
\hline Pastas & Cimento (g) & $\begin{array}{c}\text { Cinza pesada } \\
\text { grossa (g) }\end{array}$ & $\begin{array}{c}\text { Cinza pesada } \\
\text { média (g) }\end{array}$ & $\begin{array}{c}\text { Cinza pesada } \\
\text { fina (g) }\end{array}$ & $\begin{array}{c}\text { Água } \\
\mathbf{( g )}\end{array}$ & $\begin{array}{c}\text { Água/aglomerante } \\
\text { (g/g) }\end{array}$ \\
\hline Ref.0,35 & 1491,40 & - & - & - & 521,99 & 0,35 \\
\hline 10\%C.G.0,35 & 1357,01 & 119,37 & - & - & 516,73 & 0,35 \\
\hline 30\%C.G.0,35 & 1079,18 & 366,15 & - & - & 505,87 & 0,35 \\
\hline 50\%C.G.0,35 & 788,58 & 624,29 & - & - & 494,50 & 0,35 \\
\hline 10\%C.M.0,35 & 1355,18 & - & 123,07 & - & 517,39 & 0,35 \\
\hline 30\%C.M.0,35 & 1074,72 & - & 376,45 & - & 507,91 & 0,35 \\
\hline 50\%C.M.0,35 & 783,03 & - & 639,98 & - & 498,05 & 0,35 \\
\hline 10\%C.F.0,35 & 1354,04 & - & - & 125,37 & 517,79 & 0,35 \\
\hline 30\%C.F.0,35 & 1071,95 & - & - & 382,84 & 509,18 & 0,35 \\
\hline 50\%C.F.0,35 & 779,61 & - & - & 649,68 & 500,25 & 0,35 \\
\hline Ref.0,40 & 1387,90 & - & - & - & 555,16 & 0,40 \\
\hline 10\%C.G.0,40 & 1263,73 & 111,16 & - & - & 549,95 & 0,40 \\
\hline 10\%C.M.0,40 & 1261,91 & - & 114,60 & - & 550,60 & 0,40 \\
\hline 10\%C.F.0,40 & 1260,78 & - & - & 116,74 & 551,01 & 0,40 \\
\hline
\end{tabular}

\subsection{Análise térmica diferencial}

O equipamento utilizado para as análises termogravimétricas foi um analisador térmico simultâneo SDT Q600, de marca TA Instruments, com o uso de cadinhos de alumina sem tampa. As massas das amostras variaram entre 18 e $20 \mathrm{mg}$. Foi utilizado gás nitrogênio 5.0 analítico para purga dos gases volatilizados (100 $\mathrm{ml} /$ minuto). A taxa de aquecimento foi de $10^{\circ} \mathrm{C} /$ minuto entre $23^{\circ} \mathrm{C}$ e $1000^{\circ} \mathrm{C}$. A análise termogravimétrica foi empregada com o objetivo de estimar o percentual de hidratos, de hidróxido de cálcio e de carbonato de cálcio nas pastas $[19,20])$.

Para determinação do teor de hidróxido de cálcio liberado na hidratação do cimento, para dada relação a/ag e idade de hidratação, aplicou-se o fator que relaciona a massa molecular do hidróxido de cálcio e a massa molecular da água, conforme a equação (1).

$$
\mathrm{Ca}(\mathrm{OH})_{2}=\frac{\mathrm{M}_{\mathrm{Ca}(\mathrm{OH})_{2}}}{\mathrm{M}_{\mathrm{H}_{2} \mathrm{O}}} \cdot \mathrm{H}_{2} \mathrm{O}=\frac{74}{18} \cdot \mathrm{H}_{2} \mathrm{O}=4,11 \cdot \mathrm{H}_{2} \mathrm{O}
$$

onde:

$\mathrm{Ca}(\mathrm{OH})_{2}$ : é o teor de hidróxido de cálcio (\%); 
$M_{\mathrm{Ca}(\mathrm{OH})_{2}}$ : é a massa molecular do hidróxido de cálcio (74);

$M_{\mathrm{H}_{2} \mathrm{O}}$ : é a massa molecular da água (18);

$\mathrm{H}_{2} \mathrm{O}$ : é a perda de massa referente à decomposição do hidróxido de cálcio (\%).

O teor de carbonato de cálcio presente nas amostras foi determinado de forma análoga ao teor de hidróxido de cálcio, conforme a equação 2.

$\mathrm{CaCO}_{3}=\frac{\mathrm{M}_{\mathrm{CaCO}_{3}}}{\mathrm{M}_{\mathrm{CO}_{2}}} \cdot \mathrm{CO}_{2}=\frac{100}{44} \cdot \mathrm{CO}_{2}=2,27 \cdot \mathrm{CO}_{2}$

onde:

$\mathrm{CaCO}_{3}$ : é o teor de carbonato de cálcio (\%);

$M_{\mathrm{CaCO}_{3}}$ : é a massa molecular do carbonato de cálcio (100);

$\mathrm{M}_{\mathrm{CO}_{2}}$ : é a massa molecular do dióxido de carbono ou anidro carbônico (44);

$\mathrm{CO}_{2}$ : é a perda de massa referente à decomposição do dióxido de carbono (\%).

Para corrigir a carbonatação das amostras usou-se a equação 3, a qual quantifica a diferença de carbonato de cálcio encontrado no cimento e na pasta, independentemente da relação a/ag. O carbonato de cálcio formado a partir da carbonatação do hidróxido de cálcio presente nas pastas foi convertido em equivalente teor de hidróxido por meio da equação 4.

$C_{c}=C_{\text {Pasta }}-C_{\text {Cimento }}$

onde:

$C_{c}$ : é o teor de carbonato de cálcio formado pela carbonatação (\%);

$C_{\text {Pasta }}$ : é o teor de carbonato de cálcio encontrado na pasta (\%);

$C_{\text {Cimento }}$ : é o teor de carbonato de cálcio determinado no cimento anidro (\%).

$\mathrm{Ca}(\mathrm{OH})_{2}=\frac{\mathrm{M}_{\mathrm{Ca}(\mathrm{OH})_{2}}}{\mathrm{M}_{\mathrm{CaCO}_{3}}} \cdot \mathrm{C}_{\mathrm{C}} \mathrm{O}=\frac{74}{100} \cdot \mathrm{C}_{\mathrm{C}}=0,74 \cdot \mathrm{C}_{\mathrm{C}}$

onde:

$\mathrm{Ca}(\mathrm{OH})_{2}$ : é o teor de hidróxido de cálcio (\%);

$\mathrm{M}_{\mathrm{Ca}(\mathrm{OH})_{2}}$ : é a massa molecular do hidróxido de cálcio (74);

$\mathrm{M}_{\mathrm{CaCO}_{3}}$ : é o teor de carbonato de cálcio (100);

$C_{c}$ : é o teor de carbonato de cálcio formado por carbonatação.

Os percentuais de perda de massa foram corrigidos para massa residual, calcinada a $1000{ }^{\circ} \mathrm{C}$, pois a quantidade de água na amostra é variável e dependente do tempo de hidratação [8]. A correção das pastas com cinza pesada moída, para mesma base de comparação, foi realizada em função da massa residual do cimento e da cinza e suas massas de dosagem, conforme a equação 5.

$\mathrm{F}_{\text {correção }}=\frac{\mathrm{M}_{\text {cimento }} \times \mathrm{R}_{\text {cimento }}+\mathrm{M}_{\text {cinza }} \times \mathrm{R}_{\text {cinza }}}{\mathrm{M}_{\text {cimento }} \times \mathrm{R}_{\text {cimento }}}$

onde:

$F_{\text {correção }}$ : é o fator de correção para os traços com cinza;

$M_{\text {cimento }}$ : é a massa de cimento do traço (g);

$M_{\text {cinza }}$ : é a massa de cinza do traço (g);

$R_{\text {cimento }}$ : é o resíduo do cimento calcinado a $1000^{\circ} \mathrm{C}$;

$R_{\text {cinza }}$ : é o resíduo da cinza calcinada a $1000^{\circ} \mathrm{C}$.

\subsection{Calorimetria isotérmica}

O perfil de liberação de calor na hidratação das pastas foi monitorado por $72 \mathrm{~h}$, em calorímetro isotérmico Thermometric TAM AIR de oito canais, empregando-se intervalo média de leitura de $30 \mathrm{~s}$. Os ensaios foram realizados com uma porção de aproximadamente 12 g de amostra, para todas as 14 misturas definidas no programa experimental. Durante todo o período de aquisição de dados, a temperatura do equipamento foi mantida constante a $21^{\circ} \mathrm{C}$. Deve-se destacar que os resultados são apresentados em função apenas da massa de cimento, com o objetivo de se normalizar os resultados, pois a quantidade de amostras colocada no calorímetro altera a quantidade total de energia trocada dentro do equipamento. O registro dos dados de calor 
liberado iniciou-se em média após 12 min do contato da água com os materiais secos. Dessa forma, não foi possível quantificar o calor liberado para os primeiros minutos de reação, atribuído, conforme MOSTAFA e BROWN [21], à molhagem dos grãos, solubilização dos aluminatos e sulfatos, hidratação da cal livre e formação inicial de etringita.

\subsection{Teor de resíduo insolúvel}

Os resultados experimentais de resíduo insolúvel (RI) foram obtidos em amostras de pastas moídas, dos mesmos lotes liofilizados e utilizados nos ensaios de termogravimetria. Os resultados do ensaio são apresentados por meio de uma média aritmética de duas repetições. A quantificação do resíduo insolúvel consistiu em adicionar $1 \mathrm{~g} \pm$ 0,001g de amostra a $100 \mathrm{ml}$ de água deionizada, agitando-se a composição por 2 min. Adicionou-se, posteriormente, $100 \mathrm{~mL}$ de solução de ácido clorídrico (1:25), seguida de agitação enérgica por mais 30 min. Em seguida, filtrou-se a solução em papel de filtro médio e lavou-se a amostra oito vezes com uma solução de ácido clorídrico (1:50), aquecida a aproximadamente $70^{\circ} \mathrm{C}$. Após a filtragem, calcinouse a amostra a $1000^{\circ} \mathrm{C}$, por um período de 1 hora. O cálculo do percentual de resíduo insolúvel foi obtido conforme a equação 6 .

$$
\begin{aligned}
& \mathrm{RI}=\frac{\mathrm{M}_{1} \times 100}{\mathrm{M}} \\
& \text { onde: } \\
& \text { RI: resíduo insolúvel (\%); } \\
& M \text { : é a massa da amostra inicial (g); } \\
& M_{1} \text { : é a massa do resíduo calcinado (g); }
\end{aligned}
$$

\subsection{Resistência à compressão}

Os ensaios de resistência à compressão foram realizados em conformidade com a ABNT NBR 5739 [22]. Os corpos de prova foram retificados e, posteriormente, capeados com pasta de cimento e mantidos em câmara úmida até a data de rompimento.

\section{RESULTADOS}

Para a correção dos resultados encontrados nas pastas estudadas, foi realizada a análise termogravimétrica do cimento anidro utilizado, conforme apresentado na Figura 1. Destaca-se três faixas principais de perda de massa. De acordo com Taylor [8], a faixa entre $16{ }^{\circ} \mathrm{C}$ e $362{ }^{\circ} \mathrm{C}$, refere-se às decomposições do C-S-H, da gipsita, da etringita e da singenita, cuja variação total de massa é, neste texto, designada por perda de água quimicamente combinada. A faixa que compreende ao pico de $387^{\circ} \mathrm{C}$,deve-se à decomposição do hidróxido de cálcio e a faixa que contém o pico de $688^{\circ} \mathrm{C}$ corresponde à decomposição do carbonato de cálcio [20].

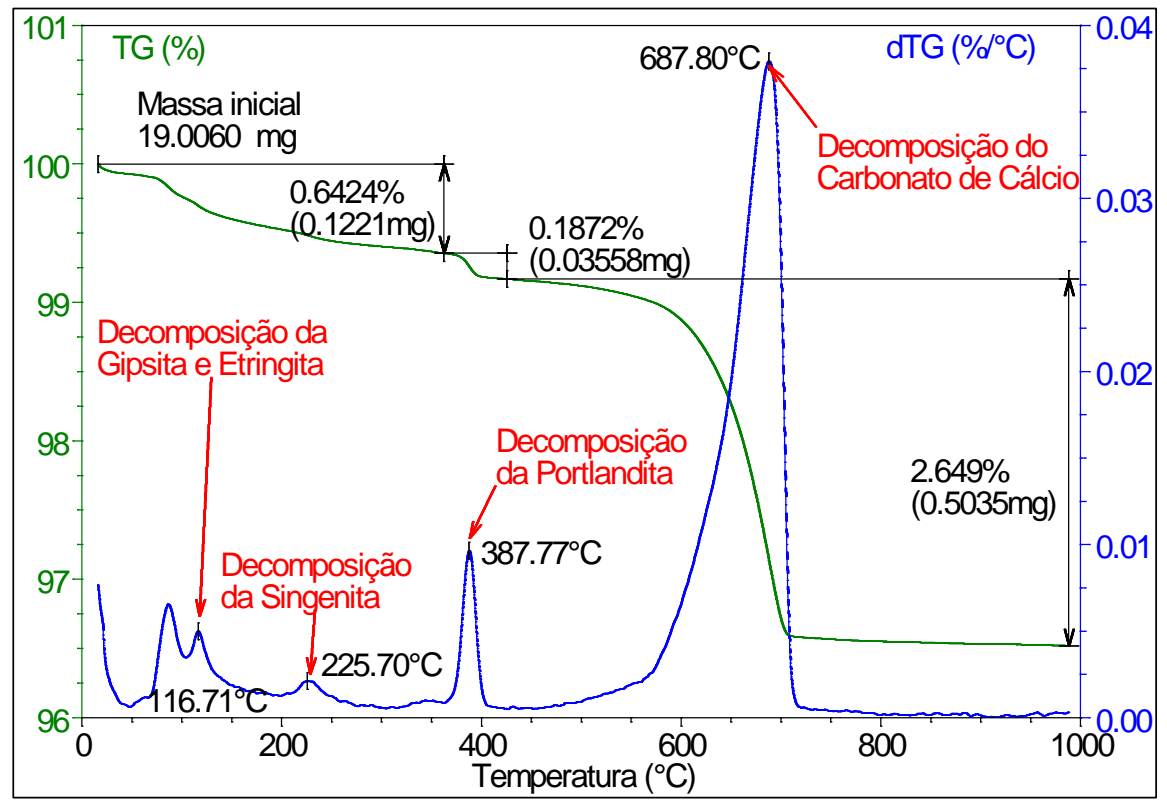

Figura 1: Termogravimetria do cimento CP V anidro. 
O teor de hidróxido de cálcio do cimento, determinado pela aplicação da Equação (1), foi de 0,77\%. A presença de hidróxido de cálcio pode estar associada à hidratação da cal livre possivelmente durante a moagem, estocagem ou a condições de queima insatisfatória. A perda de massa referente ao anidrido carbônico foi de 2,65\%. Com a aplicação da Equação (2), o teor de perda de massa atribuído ao carbonato de cálcio no cimento anidro foi de $6,01 \%$. Com relação ao resíduo calcinado a $1000{ }^{\circ} \mathrm{C}$, a cinza fina, média e grossa apresentaram, respectivamente, valores de 98,04\%; 98,27\% e 98,22\%. Cabe destacar que os três lotes de cinza apresentaram queda de massa só a partir de $550{ }^{\circ} \mathrm{C}$, com pico em $720^{\circ} \mathrm{C}$, em atmosfera inerte.

Os dados de distribuição granulométrica dos três lotes de cinza pesada moída e do cimento, junto com as massas específica de cada, são apresentados na Tabela 2. O diâmetro $\mathrm{D}_{10}$ representa um diâmetro em que $10 \%$ do volume total da amostra é composta por partículas de dimensões iguais ou inferiores ao valor especificado. $O D_{\text {máx }}$ é o maior diâmetro de partícula encontrado na amostra. Pode-se observar que o diâmetro médio das partículas do cimento é inferior a 13,67 $\mu \mathrm{m}$, enquanto a cinza fina tem um diâmetro médio inferior a 13,00 $\mu \mathrm{m}$. Nota-se, também, que o processo de moagem alterou a densidade da cinza pesada; contudo, os valores foram sempre menores do que o da massa especifica do cimento $(3,09)$. Os teores de óxido da cinza pesada e do cimento estão mostrados na Tabela 3. A somatória dos teores de $\mathrm{SiO}_{2}, \mathrm{Al}_{2} \mathrm{O}_{3}$ e $\mathrm{Fe}_{2} \mathrm{O}_{3}$ para a cinza pesada é igual a 93,05\%, indicando que a cinza pesada pode ser classifica, segundo a norma ASTM C618 [23], como uma cinza do tipo F.

Tabela 2: Parâmetros de distribuição granulométrica (\% em volume) da cinza pesada moída e do cimento CP V, obtidos por granulometria a laser.

\begin{tabular}{l|c|c|c|c|c}
\hline Material & D10 $(\boldsymbol{\mu m})$ & D50 $(\boldsymbol{\mu m})$ & D90 $(\boldsymbol{\mu m})$ & Dmáx. $(\boldsymbol{\mu m})$ & Massa específica $\left(\mathbf{g} / \mathbf{c m}^{\mathbf{3}}\right)$ \\
\hline Cimento CP V & 1,85 & 13,67 & 47,56 & 209,30 & 3,12 \\
\hline Cinza Grossa & 9,93 & 40,43 & 79,66 & 248,90 & 2,47 \\
\hline Cinza Média & 5,58 & 20,91 & 43,70 & 148,00 & 2,55 \\
\hline Cinza Fina & 2,75 & 13,00 & 33,78 & 124,50 & 2,60 \\
\hline
\end{tabular}

Tabela 3: Composição química (teores de óxidos) das cinzas pesadas ensaiadas pelo método de fluorescência de Raios-X.

\begin{tabular}{|c|c|c|c|c|c|c|c|c|c|c|}
\hline Elemento & $\mathrm{SiO}_{2}$ & $\mathrm{Al}_{2} \mathrm{O}_{3}$ & $\mathrm{Fe}_{2} \mathrm{O}_{3}$ & $\mathrm{~K} 2 \mathrm{O}$ & $\mathrm{CO}_{2}{ }^{*}$ & $\mathrm{CaO}$ & $\mathrm{TiO}_{2}$ & MgO & $\mathrm{Na}_{2} \mathrm{O}$ & $\mathrm{SO}_{3}$ \\
\hline Cimento & 19,01 & 4,40 & 2,60 & 1,65 & 2,97 & 60,44 & 0,54 & 5,10 & - & 2,85 \\
\hline Cinza Pesada & 61,60 & 22,65 & 8,80 & 2,05 & 1,70 & 1,25 & 1,30 & 0,45 & 0,25 & 0,20 \\
\hline Elemento & $\mathrm{BaO}$ & $\mathrm{ZrO}_{2}$ & $\mathrm{P}_{2} \mathrm{O}_{5}$ & MnO & $\mathrm{Rb}_{2} \mathrm{O}$ & $\mathrm{Cr}_{2} \mathrm{O}_{3}$ & Sro & Zno & $\mathrm{Nb}_{2} \mathrm{O}_{5}$ & \\
\hline Cimento & - & - & - & 0,1 & - & 0,15 & 0,12 & 0,07 & - & \\
\hline Cinza Pesada & 0,10 & 0,10 & 0,10 & 0,05 & 0,00 & 0,05 & 0,00 & 0,00 & 0,00 & \\
\hline
\end{tabular}

Na Figura 2 é apresentado o espectro de raios-X da cinza pesada, in natura, empregando-se o equipamento de marca Rigaku, modelo Miniflex II Desktop X-Ray Difractometer, com radiação Cu K-alfa; $\lambda=1,5406 \AA ; 5^{\circ} \leq 2 \theta \leq 85^{\circ}$ com passo de $0,01^{\circ}$ por segundo. Duas lâminas foram ensaiadas com a porção passante na peneira com abertura de malha de 0,075 , sem haver moagem no preparo das amostras. As fases cristalinas identificadas foram quartzo, mulita e hematita. Os resultados da análise pelo método Rietveld multicomponente indicaram que o percentual de componentes amorfos da cinza é de 60\%. 


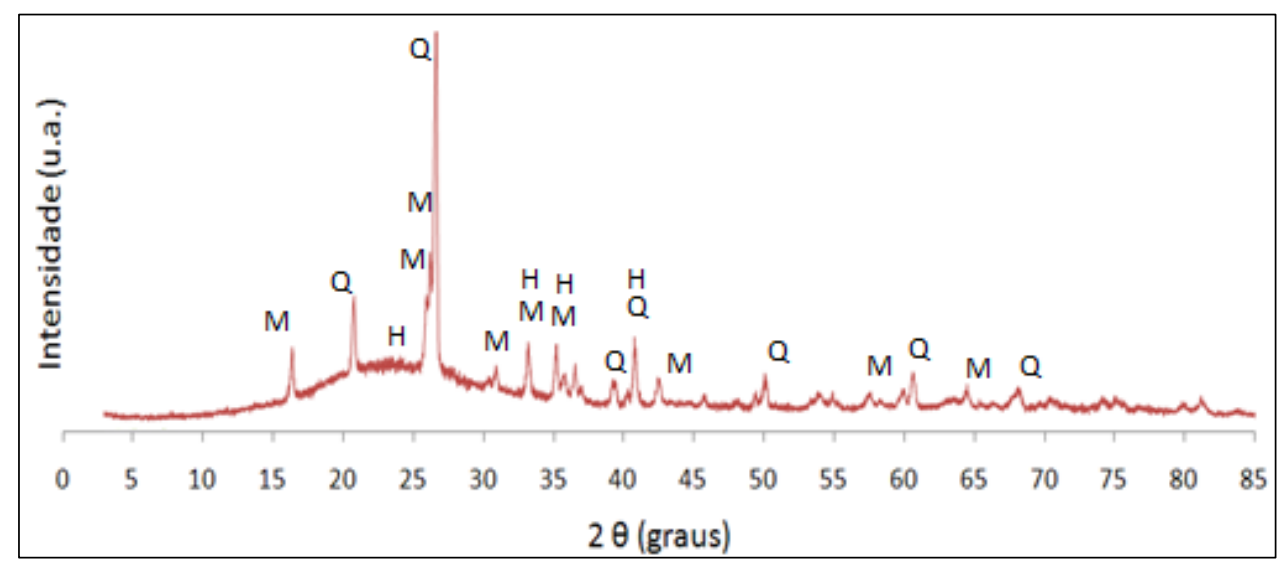

Figura 2: Espectros de Raios-X obtidos para as cinzas pesada moída - (Q) quartzo, (M) mulita e (H) hematita.

\subsection{Termogravimetria}

Em relação à pasta referência, as pastas com cinza pesada moída e a/ag de 0,35 apresentaram aumento no teor de hidróxido de cálcio e de água quimicamente combinada, conforme mostra a Figura 3. Tomando-se como exemplo a mistura com 50\% de cinza fina, após 91 dias de hidratação houve aumento de 120,2\% no teor de hidróxido de cálcio, ao mesmo tempo que se verificou aumento de 34,5 \% na água quimicamente combinada.

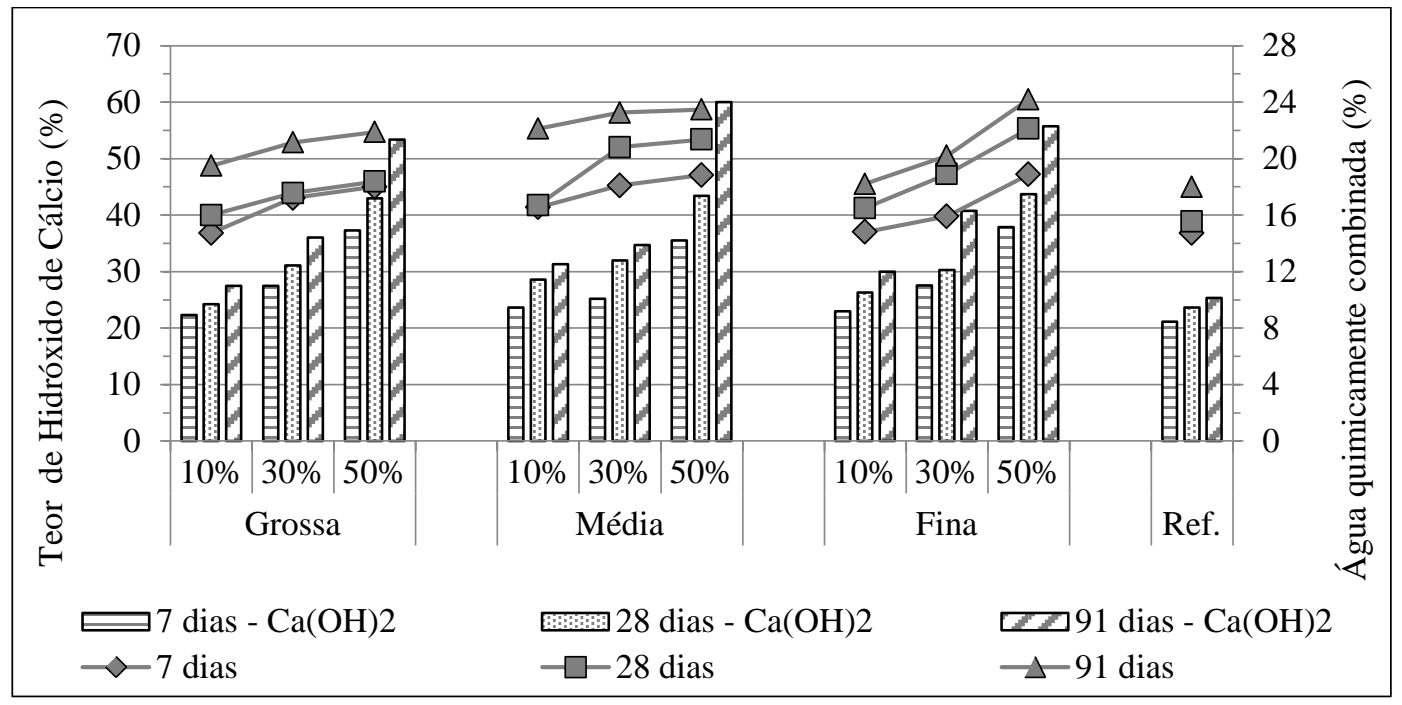

Figura 3: Teores de hidróxido de cálcio (\%) e de água quimicamente combinada (\%) para as pastas com a/ag 0,35, obtidos por análise termogravimétrica.

De modo geral, em relação à pasta referência, houve acréscimo no teor de hidróxido de cálcio em função do tempo de hidratação e do teor de substituição para o mesmo lote de cinza. Como exemplo, a mistura com 50\% de cinza fina apresentou acréscimos no teor de hidróxido de cálcio de 79,3; 85,1 e 120,2 \% para as idades de 7, 28 e 91 dias, respectivamente. Do mesmo modo, as misturas com 10\%, 30\%, e 50\% de cinza fina, aos 91 dias de hidratação, apresentaram acréscimos de 18,6; 60,9 e 120,2 \%, respectivamente. Houve influência, também, do tamanho das partículas da cinza pesada. As pastas produzidas com cinzas fina e média apresentaram os maiores teores de hidróxido de cálcio em comparação com as pastas produzidas com cinza grossa. Após 91 dias de hidratação, a pasta com 50\% de cinza média apresentou o maior teor de hidróxido de cálcio (60,0\%), representando um acréscimo de 137,2\% em relação à pasta referência.

Os resultados de água quimicamente combinada mostraram que existiu um significativo acréscimo de produtos hidratados em função do teor de incorporação de cinza pesada moída de mesmo lote, em relação à pasta referência, e os maiores acréscimos de água quimicamente combinada ocorreram até os 28 dias. Essa tendência pode ser ilustrada pelos resultados da pasta com $30 \%$ de cinza média, a qual apresentou acréscimos de 23,0\%; 33,9\% e 29,3\% aos 7, 28 e 91 dias de hidratação, respectivamente. Esse comportamento pode ser explicado, parcialmente, pela transformação da etringita, presente nas pastas, em monosulfoaluminato de 
cálcio hidratado [8]. A água como produto dessa reação foi, possivelmente, retirada das pastas pelo processo de liofilização e, consequentemente, reduziu os percentuais de água quimicamente combinada encontrado aos 91 dias.

Para os percentuais de substituição de $10 \%$ e $30 \%$ as pastas com cinza média apresentaram os maiores teores de água quimicamente combinada, enquanto que, para o teor de $50 \%$ de substituição, os maiores teores foram encontrados nas pastas com cinza fina. A pasta com 50\% cinza fina, aos 28 dias de hidratação, apresentou o maior teor de água quimicamente combinada (22,1\%), representando um acréscimo de 42,4\% em relação ao da pasta referência.

As pastas dosadas com relação a/ag de 0,40 tiveram um aumento nos seus percentuais de água quimicamente combinada e hidróxido de cálcio, em relação as pastas referência. Conforme mostra a Figura 4, quando se compara os resultados das pastas com a/ag de 0,35 com as pastas dosadas com a/ag 0,40, nota-se acréscimo nos percentuais de hidróxido de cálcio e de água quimicamente combinada. Tomando-se como exemplo a pasta com cinza fina e a/ag 0,40, aos 91 dias de hidratação, observa-se acréscimo de 9,2\% para o teor de hidróxido de cálcio e $25,7 \%$ de água quimicamente combinada, em relação a pasta com a/ag 0,35.

Como era esperado, mais produtos de hidratação foram formados com o aumento do tempo de hidratação e o percentual de incorporação de cinza pesada moída nas pastas. As pastas dosadas com cinza média e cinza fina apresentaram os maiores acréscimos nos percentuais de hidratos em relação a pasta referência. No entanto, não foi observado uma redução no percentual de hidróxido de cálcio, seguido de um acréscimo nos percentuais de água quimicamente combinada. Isso sugere, possivelmente, que a cinza pesada moída atuou concomitantemente em duas frentes: como uma pozolanas, pelo incremento de água quimicamente combinada, e como fíler ajudando no processo de nucleação dos hidratos, traduzido pelo aumento nos percentuais de hidróxido de cálcio.

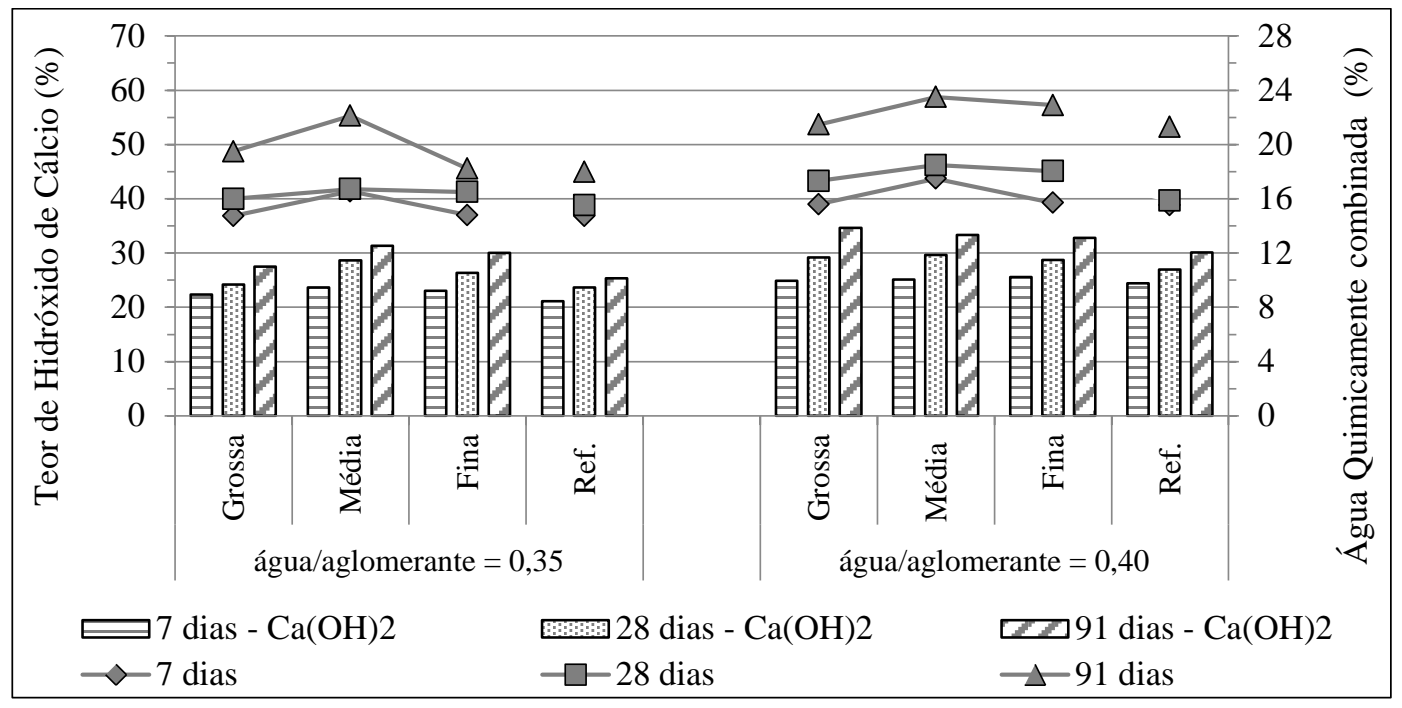

Figura 4: Teores de hidróxido de cálcio (\%) e de água quimicamente combinada (\%) para as pastas com a/ag. 0,35 e 0,40, e 10\% de substituição, obtidos por análise termogravimétrica.

\subsection{Calorimetria isotérmica}

Os resultados de taxa de liberação calor $(\mathrm{mW} / \mathrm{g})$ e calor liberado $(\mathrm{J} / \mathrm{g})$, normalizados para a massa de cimento Portland, são mostrados na figura 5, com os valores listados na Tabela 4. A normalização dos resultados permitiu avaliar a influência da cinza pesada moída no perfil de liberação de calor independente do traço e do tamanho da amostra ensaiada e, consequentemente, avaliar a influência da cinza pesada moída na cinética de hidratação do cimento.

O período de indução sofreu aumento para as misturas com a/ag de 0,35 e teor de substituição de $10 \%$, para os lotes de cinza grossa e cinza fina, enquanto as demais pastas esse período foi reduzido. Independentemente da relação a/ag, a cinza média apresentou as maiores reduções no período de indução, para cada teor de substituição. Como exemplo, a mistura com 30\% de cinza média e a/ag de 0,35 apresentou uma redução do período de indução de 5,5\%, em relação a mistura referência. Para as pastas com relação a/ag de 0,40, todos os períodos de indução foram reduzidos em até 15\% em relação ao da pasta referência. 


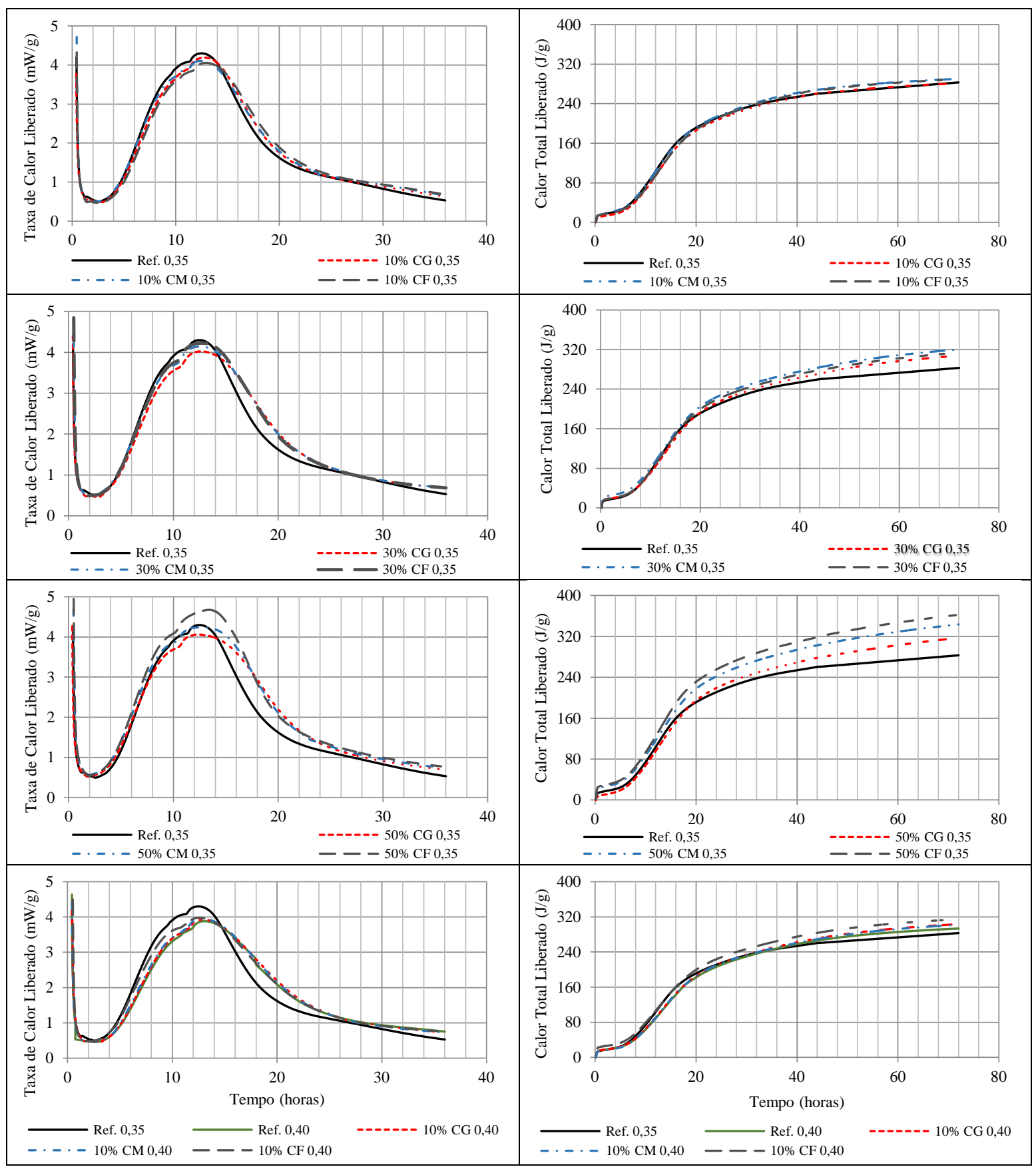

Figura 5: Resultados de calorimetria isotérmica, normalizados para a massa de cimento Portland.

Pôde-se, também, observar que o calor total liberado em 72 horas, em função da massa de cimento Portland, aumentou em função do teor de substituição de cinza pesada moída, ou seja, quando maior o teor de incorporação de cinza, maior foi a liberação de calor por grama de cimento. A mistura com 50\% de cinza fina (CF) e a/ag de 0,35, liberou 362,20 J/g, um acréscimo na liberação de calor total de 28\%, em relação a pata referência.

Os resultados de calorimetria isotérmica apresentam similaridade com os reportados na literatura para pastas de cimento e cinza volante [24, 25, 26], incluindo o aumento no período de indução. Possivelmente, as alterações do perfil de liberação de calor das pastas com adição de cinza pesada estejam associadas à adsorção dos íons $\mathrm{Ca}^{2+}$ pela superfície das cinzas, promovendo um retardo na hidratação da alita [26, 27]. 
Tabela 4: Valores referente ao período de indução e colar total liberado, normalizados para a massa de cimento Portland.

\begin{tabular}{l|c|c|c|c}
\hline Pastas & $\begin{array}{c}\text { Período de } \\
\text { Indução (h) }\end{array}$ & $\begin{array}{c}\text { Variação em relação a } \\
\text { pasta referência (\%) }\end{array}$ & $\begin{array}{c}\text { Calor total liberado } \\
\text { em 72 horas (J/g) }\end{array}$ & $\begin{array}{c}\text { Variação em relação a } \\
\text { pasta referência (\%) }\end{array}$ \\
\hline Ref. 0,35 & 4,09 & - & 283,02 & - \\
\hline $10 \%$ CG 0,35 & 4,11 & 0,48 & 281,30 & $-0,61$ \\
\hline $30 \%$ CG 0,35 & 4,05 & $-1,01$ & 307,78 & 12,03 \\
\hline $50 \%$ CG 0,35 & 3,94 & $-3,69$ & 317,07 & 2,60 \\
\hline $10 \%$ CM 0,35 & 3,94 & $-3,66$ & 290,38 & 13,22 \\
\hline $30 \%$ CM 0,35 & 4,01 & $-2,04$ & 320,44 & 21,37 \\
\hline $50 \%$ CM 0,35 & 3,87 & $-5,47$ & 343,51 & 2,28 \\
\hline $10 \%$ CF 0,35 & 4,26 & 4,13 & 289,46 & 10,91 \\
\hline $30 \%$ CF 0,35 & 4,08 & $-0,19$ & 313,90 & 27,98 \\
\hline $50 \%$ CF 0,35 & 3,90 & $-4,60$ & 362,20 & - \\
\hline Ref. 0,40 & 4,39 & - & 293,38 & 3,39 \\
\hline $10 \%$ CG 0,40 & 4,27 & $-2,82$ & 303,32 & 2,92 \\
\hline $10 \%$ CM 0,40 & 3,72 & $-15,33$ & 301,93 & 7,18 \\
\hline $10 \%$ CF 0,40 & 4,02 & $-8,40$ & 314,43 & \\
\hline
\end{tabular}

\subsection{Teor de resíduo insolúvel}

Na Figura 7 são apresentados os percentuais médios de resíduo insolúvel (RI) das pastas dosadas com relação água/aglomerante de 0,35 . Nota-se que a técnica apresentou baixa dispersão nos resultados com o desvio padrão variando entre 0,02 e 0,53 .

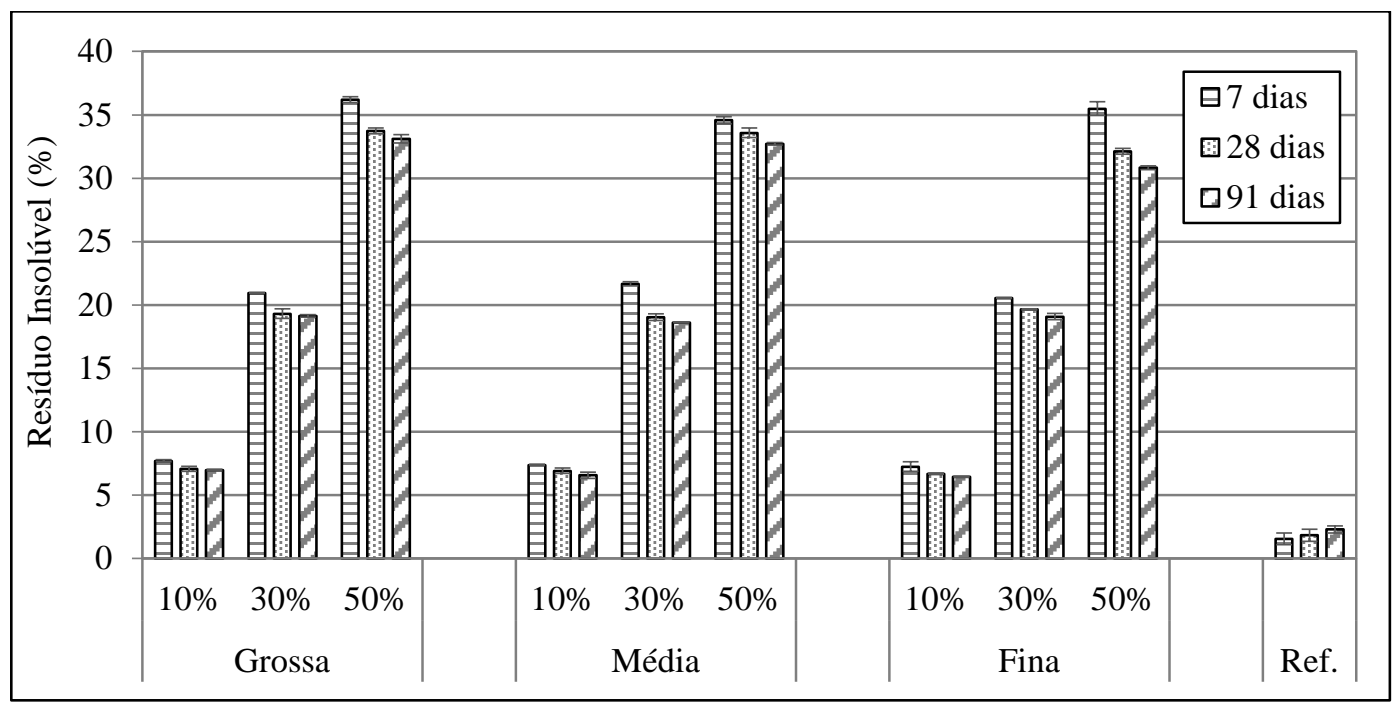

Figura 6: Percentual de RI com o respectivo desvio padrão das pastas dosadas com relação a/ag de 0,35.

Os resultados de RI indicam que a cinza pesada moída incorporada nas pastas de cimento Portland foi parcialmente consumida entre os 7 e os 91 dias de hidratação, pois admite-se que o resíduo insolúvel é composto apenas pela porção de cinza não dissolvida durante as reações de hidratação e pela fração residual do próprio cimento. Para se obter uma análise quantitativa dos valores de RI, assume-se que a cinza pesada moída apresenta baixa reatividade com o hidróxido de cálcio antes dos 7 dias de hidratação [7]. Nesse contexto a mistura com 30\% de cinza média obteve a maior redução de RI, entre os 7 e 91 dias de hidratação, apresentando um consumo de cinza de $14 \%$. Os resultados de RI para a relação água/aglomerante 0,40 não apresentaram diferença significativa para as pastas com relação a/ag igual a 0,35. Esse resultado sugere que o acréscimo de água na mistura adotado neste estudo não foi suficiente para facilitar o processo de dissolução e hidratação da 
cinza a nível de se tornar sensível no ensaio [28].

Embora não se tenha na literatura resultados a respeito do RI de pastas de cimento Portland com adição de cinza pesada moída, pode-se fazer um paralelo com estudos publicados com cinza volante. OGAWA et al. [29] encontraram valores similares de redução para a cinza volante em pastas de $\mathrm{C}_{3} \mathrm{~S}$ e cinza volante, para uma solução de ácido salicílico e metanol aos 7 e 28 dias de hidratação.

\subsection{Resistência à compressão}

Com base nos resultados de resistência à compressão, pode-se observar que as misturas com cinza média e fina obtiveram resultados superiores aos da pasta referência, aos 28 e 91 dias, para a relação a/ag de 0,35 , exceto as misturas com 50\% de cinza fina aos 28 dias e 30\% de cinza fina aos 91 dias, que tiveram uma redução de 9,0\% e 6,4\%, respectivamente, conforme mostrado na Figura 8. Os maiores percentuais de ganho de resistência mecânica, em relação a pasta referência, ocorreram aos 28 dias de hidratação. Analisando apenas as pastas com cinza média e fina, a variação média de resistência entre todos os teores para as duas cinzas, em relação a pasta referência, foi de $-20 \%, 16 \%$ e 7\%, aos 7, 28 e 91 dias de hidratação, respectivamente.

Esses resultados citados evidenciam a influência do tamanho das partículas da cinza pesada moída na resistência mecânica à compressão das amostras, a qual foi, possivelmente, influenciada pela reação pozolânica da cinza e, possivelmente, pelo melhor empacotamento dos grãos da matriz cimentícia. Nota-se, também, que pôde-se substituir em até $50 \%$ o cimento sem detrimento da resistência mecânica para as pastas com cinzas média e fina.

Embora não exista um consenso a respeito da influência da cinza pesada moída na resistência de pastas de cimento, os resultados encontrados estão em conformidade com os publicados por KULA et al. [3], os quais estudaram a incorporação de cinza pesada em argamassas como adição mineral, e observaram que a resistência à compressão das misturas aumentava, em relação a argamassa de cimento, a partir dos 28 dias de hidratação. Contudo, CHERIAF et al. [7] concluíram que argamassas com $25 \%$ de substituição de cimento por cinza pesada moída (em massa) não alcançavam a resistência à compressão da pasta referência, aos 91 dias de hidratação. Da mesma forma, KIM [15] observou decréscimo de resistência, em argamassas, para teores de substituição ao cimento de $15 \%$ e $30 \%$.

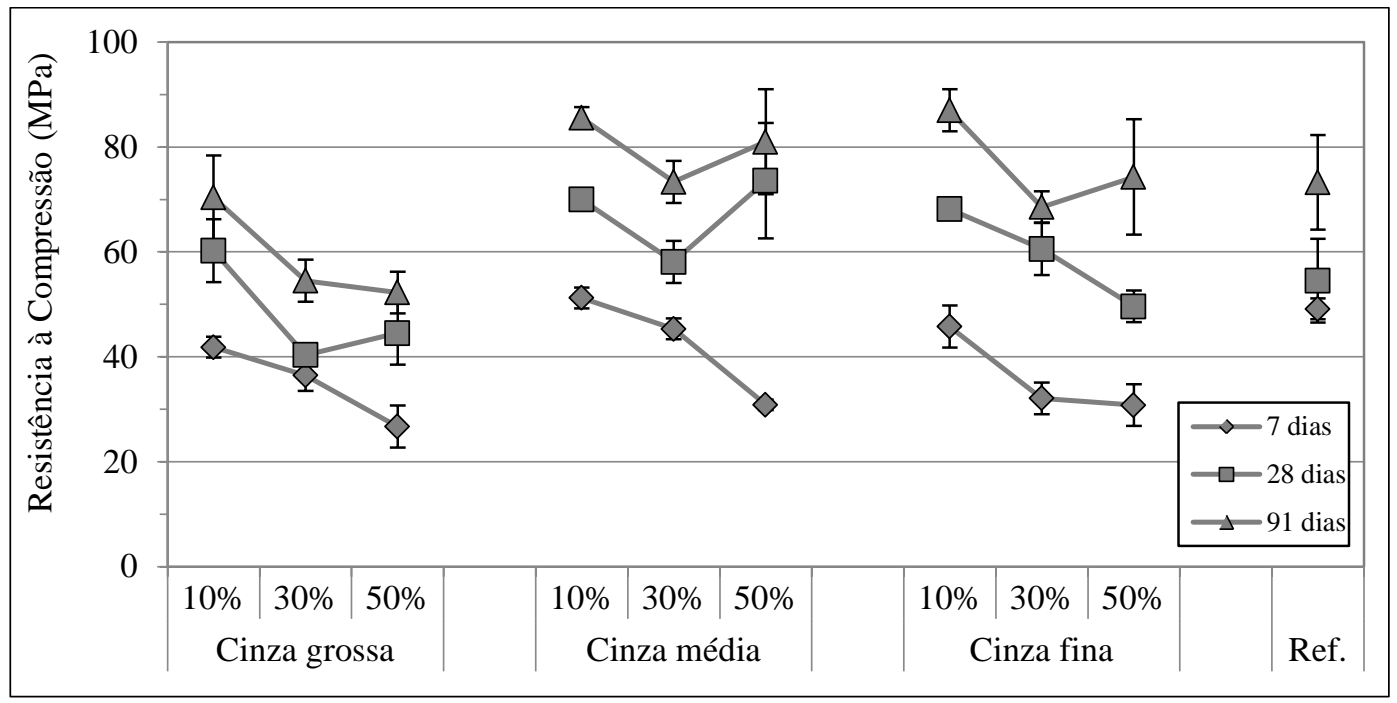

Figura 7: Resistência à compressão com o respectivo desvio padrão das pastas com relação a/ag de 0,35.

Na Figura 9 são mostrados os resultados de resistência à compressão das pastas com 10\% de substituição de cimento por cinza junto com as pastas referências, para as relações a/ag de 0,35 e 0,40. Pode-se observar que apenas as misturas com cinza fina e grossa, aos 7 e 91 dias de hidratação, respectivamente, apresentaram valores de resistência à compressão superior as misturas com relação a/ag de 0,35 . Com relação à evolução de resistência ao longo do tempo as pastas dosadas com relação a/ag 0,40 obtiveram ganhos de resistência à compressão principalmente aos 91 dias, quando comparadas com as pastas referências, enquanto que as pastas com relação 0,35 tiveram os maiores aumentos aos 28 dias. 


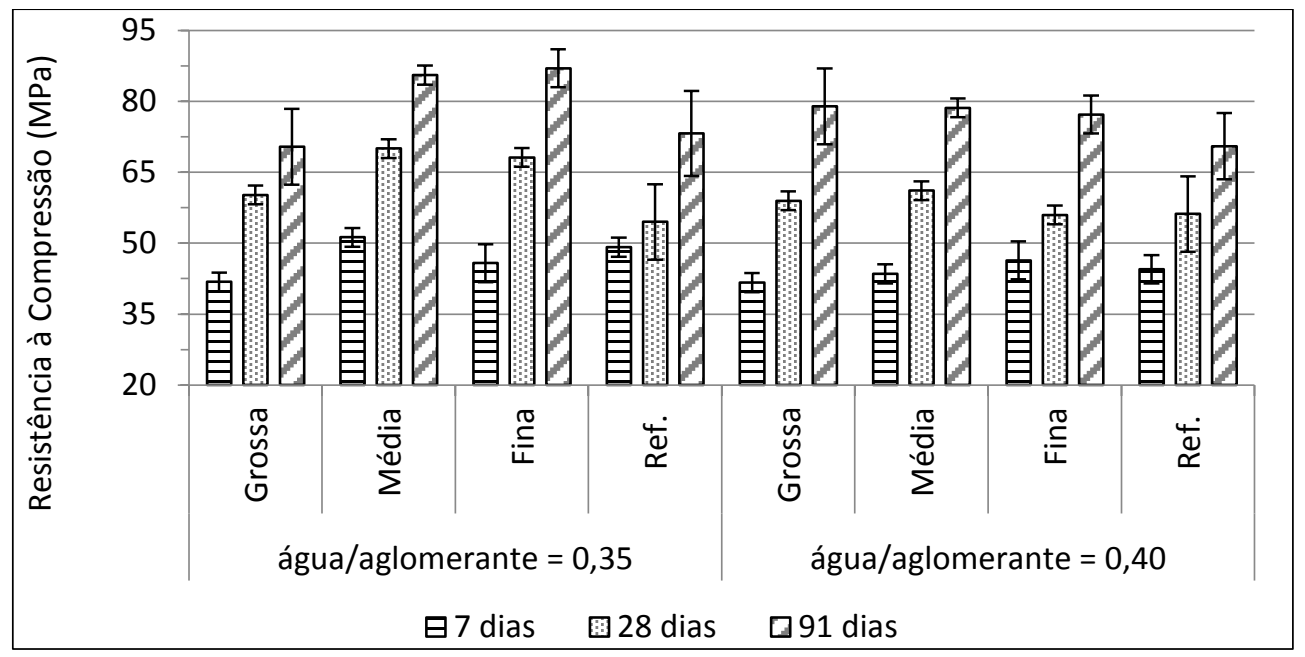

Figura 8: Resistência à compressão com o respectivo desvio padrão para as pastas com 10\% de cinza e a/ag. 0,35 e 0,40.

\section{CONCLUSÕES}

Com o estudo realizado, pode-se concluir que a incorporação de cinza pesada moída, possui um grande potencial como adição ao clínquer Portland, para composição dos cimentos pozolânicos. A incorporação de cinza pesada moída nas pastas promoveu um aumento nos produtos de hidratação por meio das ações física e química, simultaneamente.

A atividade física da cinza pesada moída foi observada pelo incremento no calor total liberado pelas pastas nas primeiras horas de hidratação e pelos acréscimos nos teores de hidróxido de cálcio encontrados nas misturas com incorporação de cinza pesada moída. A atividade química ficou evidenciada pelo incremento nos teores de água quimicamente combinada, pela redução nos percentuais de resíduo insolúvel e pelo incremento na resistência à compressão.

Avaliando de forma conjunta os resultados, nota-se que as cinzas média e fina apresentaram os melhores desempenhos nos testes realizados. No entanto, a cinza média se destaca por ter passado por um menor tempo de moagem e, consequentemente, menor consumo de energia.

\section{AGRADECIMENTOS}

A Coordenação de Aperfeiçoamento de Pessoal de Nível Superior - CAPES

ANEEL - Projeto PD 0403-0007/2008 (UFSC-Tractebel Energia).

\section{BIBLIOGRAFIA}

[1] INTERNATIONAL ENERGY OUTLOOK - IEO, U.S. Energy Information Administration. Forrestal Building Washington, D. C., 2013.

[2] AMERICAN SOCIETY FOR TESTING AND MATERIALS. ASTM C125 - 13a: standard terminology relating to concrete and concrete aggregates. Philadelphia, 2013.

[3] KULA, I., OLGUN, A., ERDOGAN, Y., et al., "Effects of colemanite waste, cool bottom ash, and fly ash on the properties of cement”, Cement and Concrete Research, v. 31, n. 3, pp 491-494, Mar. 2001.

[4] KULA, I., OLGUN, A., SEVINC, V., et al., "An investigation on the use of tincal ore waste, f ly ash, and coal bottom ash as Portland cement replacement materials", Cement and Concrete Research, v. 32, pp. 227-232, 2002.

[5] TARGANA, S., OLGUNB, A., ERDOGANB, Y., et al., "Influence of natural pozzolan, colemanite ore waste, bottom ash, and fly ash on the properties of Portland cement", Cement and Concrete Research, v. 33, pp 1175-1182, 2003.

[6] CANPOLAT, F., YILMAZ, K.., KOSE, M. M., et al., "Use of zeolite, coal bottom ash and fly ash as replacement materials in cement production”, Cement and Concrete Research, v. 34, pp 731-735, 2004.

[7] CHERIAF, M., ROCHA, J.C., PÉRA, J. "Pozzolanic properties of pulverized coal combustion botton ash”, Cement and Concrete Research, v. 29, n. 9, pp. 1387-1391, Set. 1999.

[8] TAYLOR, H. F. W., Cement cheimstry. 2a ed. London, Thomas Telford Publishing, 1997. 
[9] FU, X., WANG, Z., TAO, W., et al., “Studies on blended cement with a large amount of fly ash”, Cement and Concrete Research, v. 32, n 7, pp. 1153 - 1159, Jul. 2002.

[10] MALEK, R. I., KHALIL, Z.H., IMBABY, S. S., et al., "The contribution of class-F fly ash to the strength of cementitious mixtures”, Cement and Concrete Research, v. 35, n. 6, pp. 1152 - 1154, Jun. 2005.

[11] MEHTA, P. K., AITCIN, P. C. "Principles underlying production of high-performance concrete”, Cement, Concrete, and Aggregates, v. 12, n. 2, pp. 70-78, 1990.

[12] LAWRENCE, P., CYR, M., RINGOT, E., "Mineral admixture in mortars: Effect of inert materials on short-term hydration”, Cement and Concrete Research, v. 33, n. 12, pp. 1939-1947, Dez. 2003.

[13] GOLDMAN, A., BENTUR. A. "The influence of microfillers on enhancement of concrete strength", Cement and Concrete Research, v. 23, n. 4, pp 962-972, Jul. 1993.

[14] ISAIA, G.C., GASTALDINI, A.L.G., MORAES, R. "Physical and pozzolanic action of mineral additions on the mechanical strength of high-performance concrete”, Cement and Concrete Composites, v. 25, n 1, pp. 69-76. Jan. 2003.

[15] KIM, H. K. "Utilization of sieved and ground coal bottom ash powders as a coarse binder in highstrength mortar to improve workability”, Construction and Building Materials, v. 91, pp. 57-64, 2015.

[16] ASSOCIAÇÃO BRASILEIRA DE NORMAS TÉCNICA. NBR 5733: Cimento Portland de alta resistência inicial. Rio de Janeiro, 1991.

[17] MOUKWA, M. AÍTCIN P.C. "The effect of drying on cement pastes pore structure as determined by mercury porosimetry”, Cement and Concrete Research, v. 18, pp 745-752, Sep. 1988.

[18] KORPA, A., TRETTIN R., "The influence of different drying methods on cement paste microstructures as reflected by gas adsorption: Comparison between freeze-drying (F-drying), D-drying, P-drying and ovendrying methods”, Cement and Concrete Research, v. 36, pp 634 - 649, 2006.

[19] TAYLOR, H. F. W., TURNER, A.B. "Reactions of tricalcium silicate paste with organic liquids”, Cement and Concrete Research, v. 17, n. 4, pp. 613-623. Jul. 1987.

[20] PAYÁ, J., MONZÓ, J., BORRACHERO, M. V., et al., “Thermogravimetric Methods for Determining Carbon Content in Fly Ashes”, Cement and Concrete Research, v. 28, n.5, pp. 675-686, Mai. 1998.

[21] MOSTAFA, N. Y., BROWN, P. W. "Heat of hydration of high reactive pozzolans in blended cements: Isothermal conduction calorimetry”, Thermochimica Acta, v. 435, n 2, pp. 162-167. Set. 2005.

[22] ASSOCIAÇÃO BRASILEIRA DE NORMAS TÉCNICA. NBR 5739: Concreto - Ensaios de compressão de corpos-de-prova cilíndricos. Rio de Janeiro, 2007.

[23] AMERICAN SOCIETY FOR TESTING AND MATERIALS. ASTM C618 - 12a: Standard specification for coal fly ash and raw or calcined natural pozzolan for use in concrete. Philadelphia, 2012.

[24] LANGAN, B. W., WENG, K., WARD, M. A. "Effect of silica fume and fly ash on heat of hydration of Portland cement”, Cement and Concrete Research, v. 32, Issue 7, pp. 1045-1051, Jul. 2002.

[25] BAERT, G., HOSTE, S., SCHUTTER, D., et al., "Reactivity of fly ash in cement paste studied by means of thermogravimetry and isothermal calorimetry", Journal of Thermal Analysis and Calorimetry, v. 94, Issue 2, pp. 485-492, Set. 2008.

[26] DITTRICH, S., NEUBAUER, J., GOETZ-NEUNHOEFFER, F. "The influence of fly ash on the hydration of OPC within the first $44 \mathrm{~h}$ - A quantitative in situ XRD and heat flow calorimetry study”, Cement and Concrete Research, v. 56, pp. 129-138, Fev. 2014

[27] MASSAZZA, F. “Pozzolana and Pozzolanic Cements”, In: HEWLETT, P.C. (eds). Lea's Chemistry of Cement and Concrete, 4 ed., capítulo 10, London, Elsevier 1998.

[28] DITTRICH, S., NEUBAUER, J., GOETZ-NEUNHOEFFER, F. "The influence of fly ash on the hydration of OPC within the first $44 \mathrm{~h}$ - A quantitative in situ XRD and heat flow calorimetry study”, Cement and Concrete Research, v. 56, pp. 129-138, 2014.

[29] WANG, X.,” Effect of fly ash on properties evolution of cement based materials”, Construction and Building Materials, v. 69, pp. 32-40, 2014.

[30] OGAWA, K., UCHIKAWA, H., TAKEMOTO, K. "The mechanism of the hydration in the system C3Spozzolana”, Cement and Concrete Research, v. 10, n.5, pp. 683-696, 1980. 